\title{
Relation between the Compaction Rate and Physical and Mechanical Properties of Particleboards
}

\author{
Fabricio Moura Dias ${ }^{\mathrm{a}}$, Maria Fátima do Nascimento ${ }^{\mathrm{b}}$, Mariano Martinez-Espinosa ${ }^{\mathrm{c}}$, \\ Francisco Antonio Rocco Lahr ${ }^{\mathrm{b}}$, Ivaldo de Domenico Valarelli ${ }^{\mathrm{d}}$ \\ ${ }^{a}$ Interunit Area of Materials Sciences and Engineering, University of São Paulo - USP, \\ Av. Trabalhador Sãocarlense, 400, Centro, 135666-590 São Carlos - SP, Brazil \\ ${ }^{\mathrm{b}}$ São Carlos School of Engineering, University of São Paulo - USP \\ ${ }^{\mathrm{C}}$ Department of Statistics, ICT, Federal University of Mato Grosso - UFMT \\ ${ }^{\mathrm{d}}$ Bauru College of Engineering, Paulista State University - UNESP
}

Received: December 2, 2004; Revised: June 16, 2005

\begin{abstract}
The compaction rate, the relation between the density of the wood panel and the density of the wood used for producing the particles, is an indicator of the product's densification. Among the various types of wood panels, particleboards are widely employed in the lumber industry, mainly for the furniture production. This paper presents a study of the relation between the compaction rate and the properties of tensile strength perpendicular to surface, Modulus of Rupture (MOR) and Modulus of Elasticity (MOE) obtained from a static bending test, thickness swelling and water absorption ( 2 and 24 hours). These properties were calculated according to the Brazilian ABNT, NBR 14810 standard. Particleboards were produced using the species Pinus elliotti and adhesive ureaformaldehyde. The relation was established by a multiple linear regression, and the most appropriate statistical models were determined. The estimated models indicate statistically significant effects of water absorption in 2 hours and MOR in the particleboards' compaction rate.
\end{abstract}

Keywords: particleboards, compaction rate, multiple regression

\section{Introduction}

Wood density is a determining factor in particleboard density. The latter density, in turn, determines the physical and mechanical properties of the particleboard panel.

Particleboards consist of a mixture of wood particles and adhesive. In the production of particleboards, after the wood is reduced to particles, the adhesive is added, thus forming a mattress. This mattress is then pressed with temperature control and under a given pressure.

The amount of material required to form the mattress is calculated based on weight. A lower density wood will lead to form a thicker mattress. The compaction rate establishes the relation between the wood density and the particleboard density.

The densities most commonly used in particleboard production vary from 0.30 to $0.50 \mathrm{~g} / \mathrm{cm}^{3}$. Higher density species can be used in combination with lower density ones.

Wood density is the most important variable to take into account, since the quality of the particleboard depends on it. The simplest way to improve the properties of wood panels is by increasing their specific weight, which can be done by varying the compaction rate.

A low density wood provides a high density compaction rate and, therefore, a higher contact surface between the particles than high density wood. This leads to a more uniform product with a greater capacity to transmit loads between the particles, resulting in higher flexural and internal bonding properties in particleboards made of low density wood.

This work investigated the relations between the compaction rate and the physical and mechanical properties of particleboards produced on a laboratory scale.

\section{Wood Particle Boards}

Wood particle boards, or particleboards, are panels made of particles of wood. The wood is reduced to chips, which are transformed into particles, that are conducted to a drying process. The dry material is mixed with a synthetic resin and the mixture is placed in a press, where it is subjected to heat and pressure, resulting in a particleboard ${ }^{1}$.

According to Maloney ${ }^{2}$, the Modulus of Elasticity and Modulus of Rupture (MOE and MOR) are strongly influenced by the particleboard's compaction rate, particle geometry, percentage of adhesives and density.

The moisture content and its distribution in the mattress also contribute substantially to the board's final properties. If there is a variation in the density of the layers in the mattress, the layers with a higher moisture content will be denser. This particleboard will exhibit greater flexural strength and stiffness properties than boards from a uniform moisture content throughout the mattress.

\subsection{Compaction rate}

The good quality of a particleboard depends on the wood density. The properties of particleboards can be improved by increasing the specific weight of the board, variation in compaction rate $^{2}$. Geimer, apud Oliveira and Freitas ${ }^{3}$, states that there is always a greater swelling in thickness when the density of the board increases.

The basic requirement for a species to be used in the fabrication of particleboards is its low density, so that the compaction rate, i.e., the relation between the density of the board and that of the wood, is at least 1.3. This ensures that the densification needed for the formation of the board will occur ${ }^{2,4}$. 


\section{Materials and Methods}

\subsection{Manufacture of the particleboards}

The particleboards were manufactured by particles of reforested pine, Pinus elliottii, using urea-formaldehyde as the glue. The density of Pinus elliottii is $0.57 \mathrm{~g} / \mathrm{cm}^{3}$ by the moisture content of $12 \%$. This wood species and adhesive are widely employed in the production of particleboards by the Brazilian industry.

The composition of the urea-formaldehyde adhesive requires additives (water and ammonium sulfate). Water acts as a solvent, reducing the viscosity of the adhesive, facilitating its application and increasing the area of contact with the particle surface. Ammonium sulfate is a catalyst that cures the adhesive.

A percentage of paraffin emulsion was also added to the particleboard composition for the purpose of filling possible gap not filled by the adhesive, thereby improving the board's dimensional stability by reducing its water absorption capacity. The quantities of materials used to manufacture each particleboard are listed in Table 1.

The particleboards were produced in three layers. Each face consisted of $25 \%$ of fine particles and the remainder (50\%), consisting of coarse particles, were concentrated in the core. The adhesive was applied separately on the core and surface particles, using a gluer.

The particles were distributed uniformly in a $50 \times 50 \mathrm{~cm}$ mold. The mattress was formed by placing the portion of particles corresponding to one of the faces in the mold, followed by the core portion, and topped with the second half of the fine particles to form the second external layer. The mattress was then pre-pressed to reduce its height, after which it was pressed for 10 minutes at $140{ }^{\circ} \mathrm{C}$ and a pressure of $40 \mathrm{kgf} / \mathrm{cm}^{2}$. The press was closed for 2 minutes. Figure 1 illustrates the particleboard manufacturing stages.

After pressing, the boards were piled up and allowed to cool at room temperature. Then, they were sawn, sanded and cut into $45 \times 45 \times 1.4 \mathrm{~cm}$ pieces. These pieces were allowed to rest for two weeks to complete the adhesive curing process, after which test specimens were taken from them.

Twelve particleboards were produced with different densities, thus creating different compaction rates. Five test specimens were taken from each particleboard to analyze each property.

\subsection{Tests}

The physical and mechanical properties, obtained according to the ABNT/NBR $14810-3^{5}$ standard, were:

- Particleboard density $-d_{p}$;

- Wood density $-\mathrm{d}_{\mathrm{w}}$;

- Tensile strength perpendicular to surface - Tp;

- Modulus of Rupture - MOR and Modulus of Elasticity - MOE to static bending;

- Water absorption (2 and 24 hours) $-\mathrm{A}_{2}$ and $\mathrm{A}_{24}$; and

- Thickness swelling (2 and 24 hours) $-\mathrm{S}_{2}$ and $\mathrm{S}_{24}$.

The compaction rate (CR) was calculated based on Equation 1.

$$
C R=\frac{d_{p}}{d_{w}} x 100
$$

where: $\mathrm{CR}=$ compaction rate $(\%) ; \mathrm{d}_{\mathrm{p}}=$ particleboard density $\left(\mathrm{g} / \mathrm{cm}^{3}\right)$; and $\mathrm{d}_{\mathrm{w}}=$ wood density $\left(\mathrm{g} / \mathrm{cm}^{3}\right)$.

Table 1. Quantity of materials for the manufacture of the particleboards.

\begin{tabular}{ll}
\hline \multicolumn{1}{c}{ Materials } & \multicolumn{1}{c}{ Amounts } \\
\hline Particles & $1660 \mathrm{~g}$ \\
Adhesive & $10 \%$ of particles' weight \\
Water & $5 \%$ of adhesive's weight \\
Ammonium sulfate & $5 \%$ of adhesive's weight \\
Paraffin emulsion & $1.5 \%$ of particles' weight \\
\hline
\end{tabular}

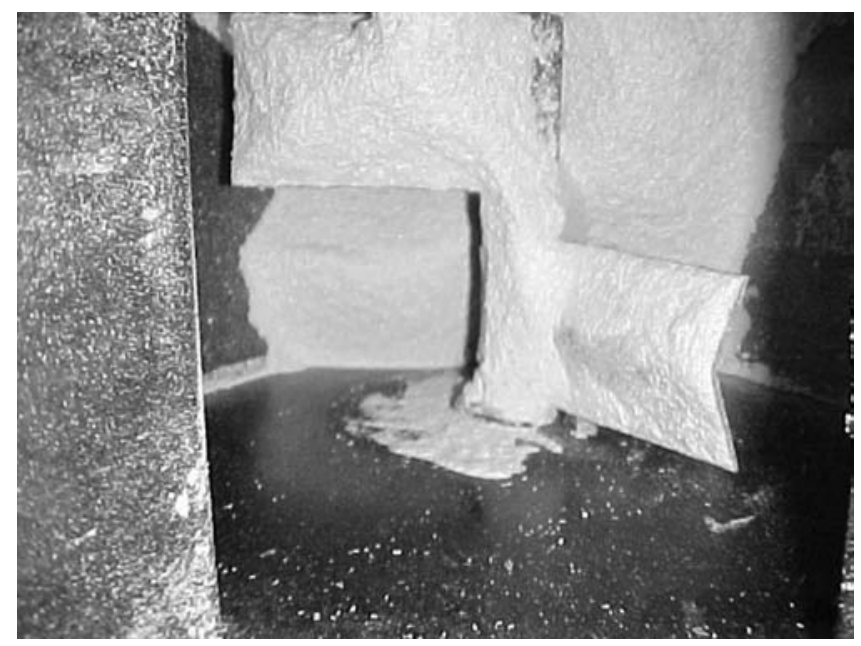

(a)

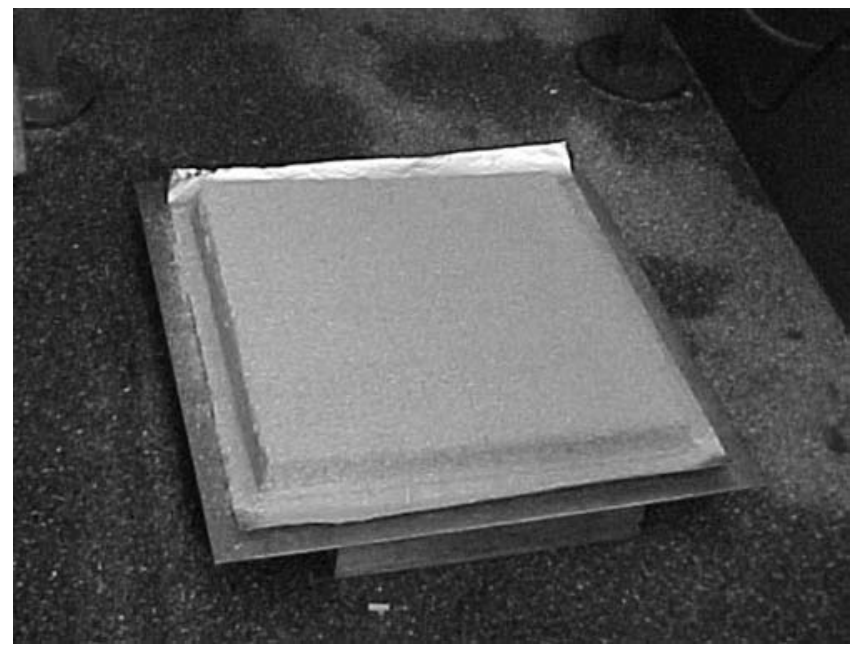

(b)

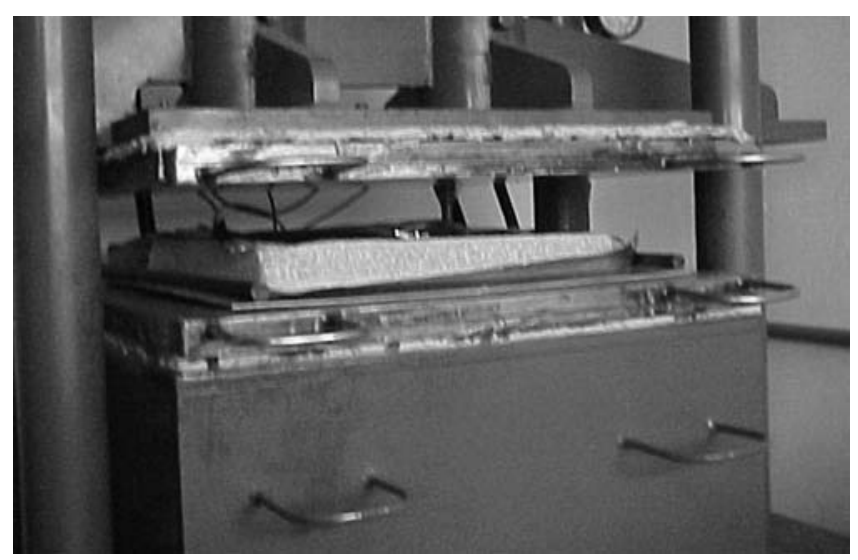

(c)

Figure 1. Production stages of the particleboards: a) interior of the gluer - mixture of wood particles with the adhesive and the paraffin; b) mattress; and c) preparation for the press. 
The dimensions of the test specimens were as follows: for density, moisture content and perpendicular tension, $5.0 \times 5.0 \mathrm{~cm}$; for water absorption and swelling, $2.5 \times 2.5 \mathrm{~cm}$; and for static bending, $5.0 \mathrm{~cm}$ width and $25 \mathrm{~cm}$ length.

\subsection{Statistic analysis}

The relation between the compaction rate and the physical and mechanical properties of the particleboards was calculated based on a multiple linear regression. This statistical method allows to compare $n$ observations of a dependent $(Y)$ variable as a function of various dependent $(k)$ variables $x_{1}, x_{2}, \ldots, x_{k}$. The multiple linear regression is presented in Equation $2{ }^{6}$.

$$
y_{i}=a_{0}+a_{1} x_{1 i}+a_{2} x_{2 i}+\ldots+a_{k} x_{k}+\varepsilon_{i}
$$

where: $\mathrm{a}_{0}, \mathrm{a}_{1}, \ldots, a_{k}$ are the parameters of the model, given by Equation 2 , also called coefficients of regression, and $\varepsilon_{i}$ are the random errors.

The $\varepsilon_{i}$ are random variables with the following suppositions:

1) The average of the $\varepsilon_{i}$ is zero and its variance $\varphi^{2}$ is unknown and constant, for $1 \leq i \leq n$;

2) The $\varepsilon_{i}$ are noncorrelated; and

3) The distribution of the $\varepsilon_{i}$ is normal, for $1 \leq i \leq n$.

To estimate the parameters of the model given by Equation 2, it is preferable to use matricial notation, since this facilitates the calculations and can be written as shown in Equation 3.

$$
\tilde{Y}=X \tilde{A}+\tilde{\varepsilon}
$$

where: $\tilde{Y}\left(y_{1}, y_{2}, \ldots, y_{n}\right)^{\prime}, X$ is a matrix $n \times k$, with $n$ lines that represent the $n$ experimental tests, $k$ is the number of independent variables, $\tilde{A}$ $i$ a vector $k \times 1$ of unknown parameters, and $\tilde{\varepsilon}=\left(\varepsilon_{1}, \varepsilon_{2}, \ldots, \varepsilon_{n}\right)^{\prime}$ are the random errors.

In this study, CR was considered a variable dependent and the other properties (MOE, MOR, Tp, $\mathrm{A}_{2}, \mathrm{~A}_{24}, \mathrm{~S}_{2}$ and $\mathrm{S}_{24}$ ) were considered the independent variables.

The effects of the independent variables were determined using the MINITAB 14 software program 7 . Regressions were made considering all the independent variables (complete model) and considering only the significant variables (reduced model).

\section{Results and Discussion}

Table 2 lists the average values of the properties identified for each particleboard.
The model that proved most appropriate was the logarithmic one. This model is presented here in two situations: the complete logarithmic model, considering all the independent variables, and the reduced logarithmic model, considering only the significant independent variables.

\subsection{Complete logarithmic model}

The complete logarithmic model is presented in Equation 4.

$$
\mathrm{CR}=-0.155+0.042 \mathrm{MOE}+0.222 \mathrm{MOR}-0.009 \mathrm{TP}
$$

$$
\text { - 0.004S2 - 0.068S24-0.164A2 + 0.055A24 }
$$

Table 3 lists the coefficients of the independent variables, with their respective standard deviations (SD), value of the rate $t(\mathrm{t})$, probability $(p)$, and number of observations $(n)$. The value $t$ indicates the significance of the variable in the model corresponding to the probability $(p)$. If the value of $p$ is lower than or equal to $5 \%(p \leq 0.05)$, the variable is accepted as significant at a level of $5 \%$.

An analysis of Table 3 shows that only the independent variables MOR and $\mathrm{A}_{2}$ present values of $p$ lower than 5\%; hence, the remaining variables (MOE, TP, $\mathrm{S}_{2}, \mathrm{~S}_{24}$ and $\mathrm{A}_{24}$ ) are not statistically significant.

Table 4 presents the analysis of variance: degrees of freedom (d.f.), sum of squares (SQ), average squares (AS), F Test (F), and probability (p). The $\mathrm{F}$ test statistically proves the existence of the regression at a significance level of $5 \%$, when $\mathrm{F}>\mathrm{F}_{\text {v1,v2.5\% }}=4.07$, through Snedecor's $\mathrm{f}$ distribution table or when $p<0.05$. The degrees of freedom of the regression and the residual error are, respectively, $v 1=7$ and $v 2=54$.

Table 3. Coefficients of regression of the independent variables DP.t.p.s.R and $n$.

\begin{tabular}{lclrc}
\hline Variables & Coefficients & \multicolumn{1}{c}{ DP } & \multicolumn{1}{c}{$t$} & $P$ \\
\hline Constant & -0.1549 & 0.7660 & -0.20 & 0.841 \\
MOE & 0.04203 & 0.06907 & 0.61 & 0.545 \\
MOR & 0.22247 & 0.08306 & 2.68 & 0.010 \\
TP & -0.00905 & 0.02608 & -0.35 & 0.730 \\
$\mathrm{I}_{2}$ & -0.00363 & 0.01988 & -0.18 & 0.856 \\
$\mathrm{I}_{24}$ & -0.06809 & 0.04589 & -1.48 & 0.144 \\
$\mathrm{~A}_{2}$ & -0.16358 & 0.03716 & -4.40 & 0.000 \\
$\mathrm{~A}_{24}$ & 0.05450 & 0.05088 & 1.07 & 0.289 \\
\hline
\end{tabular}

Table 2. Average values of the physical and mechanical properties of the particleboards.

\begin{tabular}{cccccccccccc}
\hline Panels & $\mathrm{d}_{\mathrm{p}}\left(\mathrm{g} / \mathrm{cm}^{3}\right)$ & $\mathrm{d}_{\mathrm{w}}\left(\mathrm{g} / \mathrm{cm}^{3}\right)$ & $\mathrm{CR}(\%)$ & $\mathrm{MOE}(\mathrm{MPa})$ & $\mathrm{MOR}(\mathrm{MPa})$ & $\mathrm{A}_{2}(\%)$ & $\mathrm{A}_{24}(\%)$ & $\mathrm{S}_{2}(\%)$ & $\mathrm{S}_{24}(\%)$ & $\mathrm{Tp}(\mathrm{MPa})$ \\
\hline 01 & 0.63 & 0.41 & 1.55 & 240298 & 11.2 & 17.11 & 48.15 & 5.08 & 18.18 & 0.33 \\
02 & 0.65 & 0.41 & 1.59 & 201814 & 10.7 & 14.47 & 44.29 & 6.67 & 16.21 & 0.27 \\
03 & 0.78 & 0.40 & 1.90 & 224927 & 13.1 & 6.87 & 30.38 & 6.13 & 17.27 & 0.46 \\
04 & 0.69 & 0.41 & 1.70 & 233652 & 14.6 & 12.67 & 41.13 & 6.12 & 18.42 & 0.41 \\
05 & 0.65 & 0.41 & 1.61 & 186791 & 10.6 & 9.70 & 51.03 & 5.48 & 18.39 & 0.55 \\
06 & 0.72 & 0.41 & 1.78 & 261418 & 12.9 & 12.96 & 47.65 & 4.75 & 16.14 & 0.46 \\
07 & 0.74 & 0.41 & 1.79 & 236101 & 12.5 & 11.73 & 48.56 & 4.78 & 18.86 & 0.45 \\
08 & 0.77 & 0.41 & 1.90 & 277053 & 15.2 & 6.91 & 21.52 & 1.68 & 14.65 & 0.49 \\
09 & 0.81 & 0.40 & 1.98 & 333706 & 16.1 & 7.14 & 20.14 & 3.24 & 9.97 & 0.50 \\
10 & 0.63 & 0.41 & 1.55 & 238805 & 13.4 & 30.57 & 74.86 & 7.79 & 25.98 & 0.21 \\
11 & 0.63 & 0.41 & 1.55 & 310549 & 15.5 & 30.11 & 73.48 & 9.08 & 26.22 & 0.26 \\
12 & 0.62 & 0.41 & 1.53 & 289643 & 16.6 & 28.51 & 62.64 & 10.93 & 27.86 & 0.37 \\
\hline
\end{tabular}

$\mathrm{d}_{\mathrm{p}}$ - particleboard density; $\mathrm{d}_{\mathrm{w}}$ - wood density; MOE - modulus of elasticity; MOR - modulus of rupture; $\mathrm{A}_{2}-$ water absorption in 2 hours; $\mathrm{A}_{24}-$ water absorption in 24 hours; $\mathrm{S}_{2}$ - thickness swelling in 2 hours; $\mathrm{S}_{24^{-}}$- thickness swelling in 24 hours; and Tp - tensile strength perpendicular to surface. 
Figure 2 presents the graph of the residues as a function of the adjusted values. This graph shows that the variance is constant, i.e., the points are dispersed uniformly around zero.

The test of normality of the residues shown in Figure 3 states that the residues and, hence, the response, follow a normal distribution.

Although the graph showing residues as a function of adjusted or estimated values (Figure 2) and the residue normality test (Figure 3)

Table 4. Analysis of variance and sum of squares of the independent variables.

\begin{tabular}{lrcccc}
\hline \multicolumn{1}{c}{ Variables } & g.l. & SQ & QM & F & p \\
\hline Regression & 7 & 0.461173 & 0.065882 & 28.35 & 0.000 \\
Residual error & 54 & 0.125508 & 0.002324 & - & - \\
Total & 61 & 0.586681 & - & - & - \\
MOE & 1 & 0.020675 & - & - & - \\
MOR & 1 & 0.002903 & - & - & - \\
Tp & 1 & 0.186334 & - & - & - \\
$\mathrm{S}_{2}$ & 1 & 0.125168 & - & - & - \\
$\mathrm{S}_{24}$ & 1 & 0.055752 & - & - & - \\
$\mathrm{A}_{2}$ & 1 & 0.067674 & - & - & - \\
$\mathrm{A}_{24}$ & 1 & 0.002667 & - & - & - \\
\hline
\end{tabular}

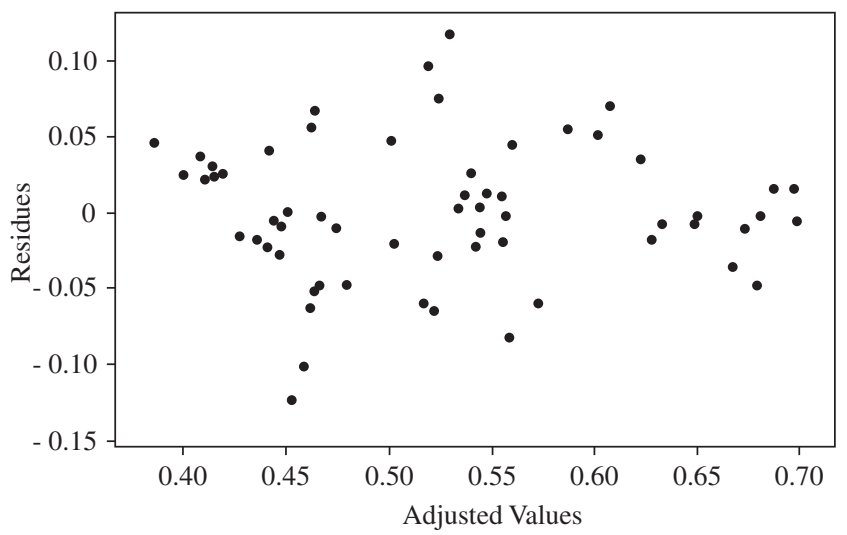

Figure 2. Graph of the residues as a function of adjusted values.

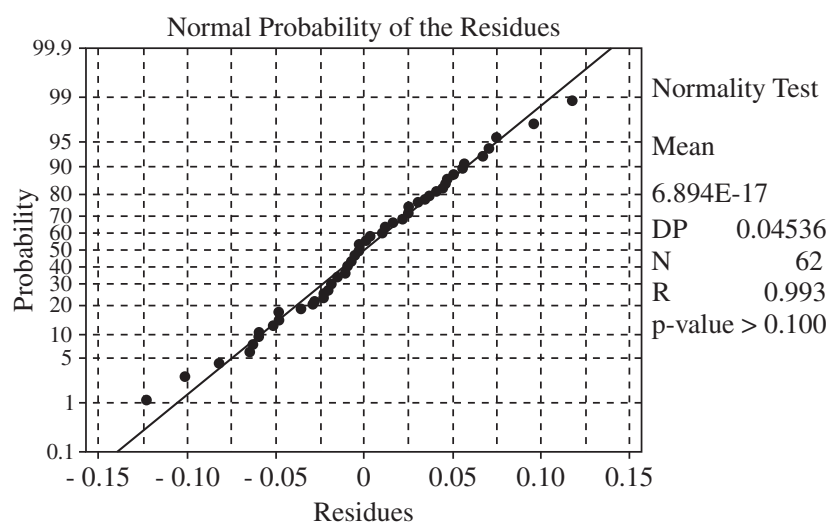

Figure 3. Graph of normal probability of the residues. confirm the validity of the complete logarithmic model, Table 3 shows that only the independent variables MOR and $A_{2}$ appeared as significant at the level of 5\%. Therefore, a regression was made (reduced logarithmic model) to establish the relation between the compaction rate and the properties of MOR (modulus of rupture in static bending) and $\mathrm{A}_{2}$ (water absorption in 2 hours).

\subsection{Reduced logarithmic model}

The reduced logarithmic model is shown in Equation 5, below.

$\mathrm{CR}=0.364+0.216 \mathrm{MOR}-0.152 \mathrm{~A}_{2}$

Table 5 lists the coefficients of the independent variables with their respective standard deviations (SD), value of rate $t(\mathrm{t})$, probability $(p)$, and number of observations $(n)$.

Table 6 presents the analysis of variance: degrees of freedom (d.f.), sum of squares (SQ), average squares (AS), F Test (F), and probability (p).

Figure 4 shows the graph of residues as a function of adjusted values.

The residue normality test is illustrated in Figure 5.

Table 5. Coefficients of regression of the independent variables DP . t . p . s. $R^{2}$ and $n$ - reduced model.

\begin{tabular}{lccrl}
\hline Variables & Coefficients & DP & $t$ & \multicolumn{1}{c}{$t$} \\
\hline Constant & 0.36380 & 0.10360 & 3.51 & 0.001 \\
MOR & 0.21647 & 0.04014 & 5.39 & 0.0 \\
$\mathrm{~A}_{2}$ & -0.15241 & 0.01116 & -13.66 & 0.000 \\
\hline$s=0.0479495$ & $R^{2}=76.9 \%$ & $\mathrm{n}=62$. & &
\end{tabular}

Table 6. Analysis of variance and sum of squares of the independent variables - reduced model.

\begin{tabular}{lrcccc}
\hline \multicolumn{1}{c}{ Variables } & g.l. & SQ & QM & F & p \\
\hline Regression & 2 & 0.45103 & 0.22552 & 28.35 & 0.0 \\
Residual error & 59 & 0.13565 & 0.00230 & - & - \\
Total & 61 & 0.58668 & - & - & - \\
MOR & 1 & 0.02183 & - & - & - \\
$\mathrm{A}_{2}$ & 1 & 0.42920 & - & - & - \\
\hline
\end{tabular}

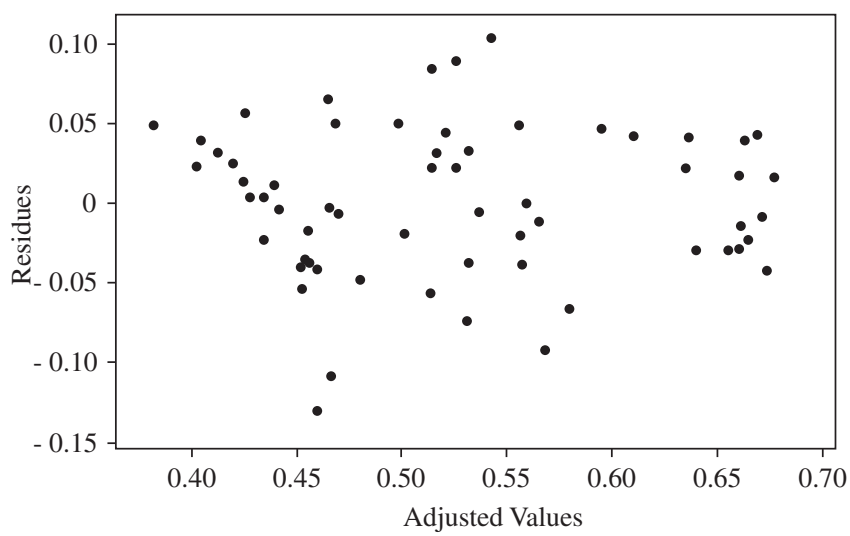

Figure 4. Graph of the residues as a function of adjusted values - reduced model. 


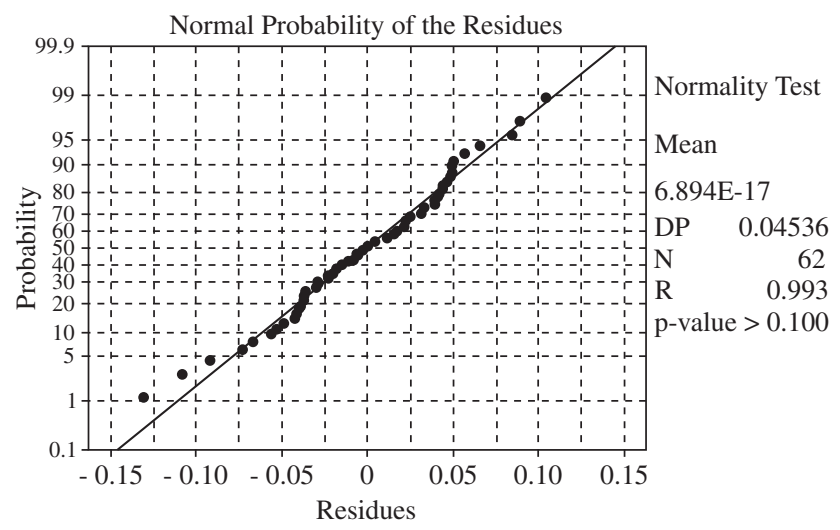

Figure 5. Graph of normal probability of the residues - reduced model.

\section{Conclusions}

The model estimated by Equation 4 indicates that the compaction rate of particleboards depends in a statistically significant way on the variables of modulus of rupture in static bending and water absorption in 2 hours. In other words, the effect of the first variable increases the compaction rate, while the effect of the second variable reduces the compaction rate. It should be pointed out that the effect of the second variable is statistically more significant (Table 3). The other independent variables are not statistically significant, that is, they do not affect the compaction rate, according to the data analyzed here.

Because the independent variables MOE, $\mathrm{A}_{24}, \mathrm{~S}_{2}$ and $\mathrm{S}_{24}$ are not statistically significant, the reduced estimated model (Equation 5) should be adopted, which presents the effect of the modulus of rupture in static flexure and absorption in 24 hours on the compaction rate.

\section{Acknowledgments}

The authors gratefully acknowledge the financial support of the Brazilian research funding agency $\mathrm{CNPq}$.

\section{References}

1. Tomaselli I. Tendências de mudanças na indústria de painéis. Revista da madeira. 2000; p. 36-40.

2. Maloney TM. Modern particleboard \& dry-process fiberboard manufacturing. revised ed. California: Miller Freeman Publications; 1977.

3. Oliveira JT, Freitas AR. Painéis à base de madeira. Boletim técnico BT/PCC/149. Escola Politécnica da Universidade de São Paulo. EPUSP. 1995; 44 p.

4. Iwakiri S. Painéis de Madeira: características tecnológicas e aplicações. Revista da madeira. 2003; Edição especial.

5. Associação Brasileira de Normas Técnicas (ABNT). NBR 14810/3 Chapa de madeira aglomerada. 2002; Rio de Janeiro. 27 p.

6. Draper NR, Smith H. Applied Regression Analysis. Revised ed. New York: John Wiley \& Sons; 1998.

7. Minitab. Minitab statistical software. Minitab Inc, release 14. Available from: http://www.minitab.com. 